\title{
Hourglass sector zoning in metamorphic tourmaline and resultant major and trace-element fractionation
}

\section{Vincent J. van Hinsberg, ${ }^{1, *}$ John C. Schumacher, ${ }^{1}$ Stuart Kearns, ${ }^{1}$ PaUl R.D. Mason, ${ }^{2}$ and GERHARD FRANZ ${ }^{3}$}

${ }^{1}$ Department of Earth Sciences, University of Bristol, Wills Memorial Building, Queens Road, BS8 1RJ, Bristol, U.K.

${ }^{2}$ Faculteit Aardwetenschappen, Universiteit Utrecht, Budapestlaan 4, 3584 CD, Utrecht, The Netherlands

${ }^{3}$ Fachgebiet Petrologie, Technische Universität Berlin, D 10623 Berlin, Germany

\begin{abstract}
A new type of sector zoning, with an hourglass shape, has been identified in metamorphic tourmalines that formed under a wide variety of physical and chemical conditions. The two sectors in the c-direction are not equivalent due to asymmetry in the crystal structure of tourmaline along the c-axis. The $\mathbf{c}^{+}$sector is characterized by low concentrations of $\mathrm{Ti}, \mathrm{Ca}, \mathrm{Mg}$, and $\mathrm{Na}$, although $\mathrm{Al}$ is high, and has a pale (commonly blue or pale-green) color. Conversely, the $\mathbf{c}^{-}$sector is low in $\mathrm{Mg}$ and $\mathrm{Al}$, and high in $\mathrm{Ca}, \mathrm{Fe}$, and $\mathrm{Ti}$ (the latter two causing the dark-brown color of this sector). The a-sector has intermediate characteristics and probably approximates a sector-free tourmaline. Thin sectioning of these sector-zoned tourmalines perpendicular to the $\mathbf{c}$-axis can produce three types of apparent radial zoning patterns: blue-green cores, dark-brown cores, or no distinct cores. These apparent cores will further vary in relative diameter depending on the sectioning level. Furthermore, "core" boundaries can be straight or ragged depending on whether the relative growth speeds for the different faces was constant or variable. These textures have been used to argue for a prograde or detrital origin of tourmaline cores. However, sector zoning is a more appealing explanation for most of these textures, and can further explain the textural resemblance among metamorphic tourmalines from highly variable bulk-rock composition, metamorphic history, and mineral paragenesis. The sector zoning that is described here develops by preferential uptake of elements on the $\mathbf{r}$ growth plane, resulting from a combined effect of differences in surface charge and morphology of this plane in the $\mathbf{c}^{+}$and $\mathbf{c}^{-}$directions. This leads to the preferential incorporation of more positively charged elements in the $\mathbf{c}^{-}$direction, and a preference for a vacant $\mathrm{X}$-site in the $\mathbf{c}^{+}$direction. Because the compositional differences among the sectors are pronounced in both major and trace elements and in the same order of magnitude as growth zoning variability, the presence of sector zoning must be established and taken into account when making inferences from tourmaline chemistry.
\end{abstract}

Keywords: Hourglass, sector zoning, tourmaline, metamorphic rocks, element fractionation 